\title{
Gain Augmentation of a HMSIW Based Equilateral Triangular Antenna using CRSF FSS Superstrate
}

\author{
Soumen BANERJEE, Biswarup RANA, Susanta Kumar PARUI \\ Dept. of Electronics and Telecommunication Engineering, Indian Institute of Engineering Science and Technology, \\ Shibpur, Howrah-711103, India
}

prof.sbanerjee@gmail.com, biswaruprana@gmail.com,arkapv@yahoo.com

Submitted March 26, 2017 / Accepted October 3, 2017

\begin{abstract}
In this paper, a half-mode substrate integrated waveguide (HMSIW) based equilateral triangular antenna is initially designed to operate at $6.5 \mathrm{GHz}$ wireless frequency. This parent antenna is fitted with metallic vias all along two of its sides to make them perfect electrical conductor (PEC) walls while radiation taking place from the other side acts as perfect magnetic conductor (PMC) wall being devoid of such metallic vias. The antenna exhibits a gain of $5.5 \mathrm{dBi}$ at the fundamental $T E_{101}$ mode with linear polarization. Its gain is augmented using polarization independent coupled-resonator spatial filter (CRSF) frequency selective surface (FSS) as superstrate and is found to increase to $8.7 \mathrm{dBi}$ at the same $6.5 \mathrm{GHz}$ resonating frequency. The antenna prototype along with the FSS structure are both fabricated using Arlon AD270 substrate and experimental measurements are carried out. It is observed that both simulated and measured results are in close agreement with each other.
\end{abstract}

\section{Keywords}

Antenna gain, coupled-resonator spatial filter (CRSF), frequency selective surface (FSS), half-mode SIW (HMSIW), substrate integrated waveguide (SIW).

\section{Introduction}

With the ever increasing demand for wireless based communication devices, antennas suitable for such applications are in utmost need. Antennas are widely used in almost every sphere spanning from wireless communication system to remote sensing, radar systems, satellite communication, biological and medical systems, industrial plants, space exploration etc. A new addition to antenna development is the use of substrate integrated waveguide (SIW) technology. SIW is a modern cutting edge state-ofthe-art chosen for its widespread use and prolific applications in the field of communication engineering. This technology replaces the conventional use of metallic waveguides by upholding their advantages like high quality factor and high power handling capability and yet providing a perfect platform for system-in-package or system-on- substrate at large wherein several electronic components can be mounted on a single substrate [1-5]. Even though the classical waveguide technology still remains as the main stream for designing different microwave and millimeter wave systems, it is less suitable for low cost, mass production owing to being tedious, expensive in post fabrication tuning and assembling and it is herein where SIW technology fills in as it allows low-cost fabrication facility with superior quality performance. The literary work in SIW based antennas started with classical slotted wave guide antennas [6] and extended to leaky wave antennas [7], cavity back antennas [8-10], H-plane sectoral antenna [11] and several other types. If the parent SIW structure is bisected along a fictitious quasi magnetic wall preserving the field distribution of the former one, a new structure called HMSIW results. Antennas based on such structures are already reported in literature [12-18].

Frequency selective surface (FSS), the wireless counterpart of filters in microwave engineering, is very popular in communication domain owing to their ample use in antenna systems for on-board satellites or deep space exploration vehicles and also in radomes. FSS exhibits band-pass or band-stop spectral behavior depending upon the type of array elements used. Nowadays, in order to enhance the antenna performance, they are being used as superstrates or substrates [19-29]. Chen and Tao [19] for the first time proposed a dual-band FSS consisting of regular Jerusalem cross elements and studied its impact on the bandwidths and resonant frequencies of a U-slot patch antenna. Foroozesh and Shafai [20] investigated the effects of the patch-type FSS superstrate on the high-gain cavity resonance antenna. Pirhadi et al. [21] proposed an aperture coupled microstrip antenna (ACMA) coupled with square loop elements frequency selective surface (FSS) as superstrate layer producing wide frequency band for return loss and high directivity. Attia et al. [22] presented gain enhancement of a microstrip patch antenna covered with a superstrate at a proper distance in free space. Hosseini et al. [23] showed the gain enhancement of a V-band planar antenna with frequency-selective-surface as superstrate at $60 \mathrm{GHz}$ wireless band. Lee et al [24] presented a novel design of a thin frequency selective surface (FSS) type of metamaterial superstrate as an alternative to a conventional 
FSS superstrate for dual-band directivity enhancement. Zhou et al. [26] investigated the properties of a filter-antenna consisting of a monopole antenna and a conical frequency selective surface (FSS) for military applications. Rana et al [27] enhanced the gain of a dual-polarized dielectric resonator antenna (DRA) using FSS as superstrate while Chatterjee and Parui [28] used a second-order bandpass FSS to increase the gain of a wide slot antenna.

In this paper, the authors have designed an equilateral triangular antenna resembling half-mode substrate integrated waveguide (HMSIW) structure to operate at $6.5 \mathrm{GHz}$ resonating frequency for wireless communication systems. The parent antenna is built-in with arrays of metallic vias on two its sides thereby making them PEC walls while the other remains as PMC wall being devoid of any vias. Radiation taking place from the PMC edge corresponds to fundamental $\mathrm{TE}_{101}$ mode at $6.5 \mathrm{GHz}$. A coupledresonator spatial filter (CRSF) frequency selective surface (FSS) is placed above the parent antenna for gain enhancement of the later. The gain is found to increase by $3.2 \mathrm{dBi}$ for the antenna-FSS combination at the same resonating frequency. The parent antenna, the FSS structure as well as the antenna-FSS composite structure are all simulated using ANSYS make HFSS v15.0. The various antenna parameters are experimentally measured and compared with those of the simulated ones.

\section{HMSIW Equilateral Triangular Antenna}

\subsection{The Configuration}

A HMSIW equilateral triangular element is initially designed to operate at $6.5 \mathrm{GHz}$ resonating frequency for wireless applications. The sole reason for choosing such antenna is the effective reduction in antenna size for a given operating frequency. Though characterized by narrow impedance bandwidth, the antenna is well suited for developing compact arrays with reduced mutual coupling between the elements. Moreover, such antenna produces smaller radiation loss when compared to its rectangular counterpart [16-18] and the PEC-PMC wall combination reduces the antenna footprint thereby making it a compact one.

For the $\mathrm{TE}_{m n p}$ modes, the resonating frequency for the designed antenna is calculated using SIW counterpart structure formulas [31]

$$
f_{m n p}^{\mathrm{SIW}}=\frac{1}{2 \pi \sqrt{\mu \varepsilon}} \sqrt{\left(\frac{m \pi}{L_{\mathrm{eff}}^{\mathrm{SIW}}}\right)^{2}+\left(\frac{n \pi}{h}\right)^{2}+\left(\frac{p \pi}{W_{\mathrm{eff}}^{\mathrm{SIW}}}\right)^{2}} .
$$

In (1), substrate's permeability $\mu=\mu_{0} \mu_{\mathrm{r}}$, substrate's permittivity $\varepsilon=\varepsilon_{0} \varepsilon_{\mathrm{r}}, m=1,2,3, \ldots, n=1,2,3, \ldots$ and $p=$ $1,2,3, \ldots$ The SIW resonator thickness $h$ and its equivalent length and width are [4]

$$
\begin{gathered}
L_{\mathrm{eff}}^{\mathrm{SIW}}=L_{\mathrm{c}}-1.08 \frac{d^{2}}{d_{1}}+0.1 \frac{d^{2}}{L_{\mathrm{c}}}, \\
W_{\mathrm{eff}}^{\mathrm{SIW}}=W_{\mathrm{c}}-1.08 \frac{d^{2}}{d_{1}}+0.1 \frac{d^{2}}{W_{\mathrm{c}}}
\end{gathered}
$$

where $L_{\mathrm{c}}$ is the length and $W_{\mathrm{c}}$ is the width of the rectangular SIW resonator, $d$ and $d_{1}$ are the via diameter and the spacing between vias respectively. The equivalent length and width is estimated by

$$
\begin{gathered}
W_{\text {eff }}^{\mathrm{HMSIW}}=\frac{W_{\mathrm{eff}}^{\mathrm{SIW}}}{2}+\Delta W, \\
L_{\mathrm{eff}}^{\mathrm{HMSIW}}=\frac{L_{\mathrm{eff}}^{\mathrm{SIW}}}{2}+\Delta W .
\end{gathered}
$$

The additional width $\Delta W$ is estimated based on the non-linear least squares method [30], [32]

$$
\begin{aligned}
\Delta W= & h\left(0.05+\frac{0.3}{\varepsilon_{\mathrm{r}}}\right) . \\
& \ln \left(0.79 \frac{W_{\mathrm{eff}}^{\mathrm{SIW}}}{4 h^{3}}+\frac{52 W_{\mathrm{eff}}^{\mathrm{SIW}}-261}{h^{2}}+\frac{38}{h}+2.77\right) .
\end{aligned}
$$

Figure 1 represents the schematic diagram of the parent antenna built on Arlon AD270 substrate $(h=0.79 \mathrm{~mm}$, $\varepsilon_{\mathrm{r}}=2.7$ and $\tan \delta=0.002$ ). The antenna is excited with coaxial feed to generate the fundamental $\mathrm{TE}_{101}$ mode. Even though the coaxial feed generates smaller amount of spurious radiation, the choice of such feed is justified owing to hassle-free fabrication technique and better impedance matching. Metallic vias incorporated on the two edges have $1 \mathrm{~mm}$ diameter $d$ with center-to-center spacing $s$ of $1.5 \mathrm{~mm}$. Such dimensions satisfy the relations $d<\lambda_{\mathrm{g}} / 5\left(\lambda_{\mathrm{g}}\right.$ is operating wavelength) and $s \leq 4 d$ [33], [34] in order to minimize radiation loss. The antenna's electric field distribution for $\mathrm{TE}_{101}$ mode and its fabricated prototype are depicted in Fig. 2. The electric field is distributed across the entire antenna surface within the via boundaries with maximum radiation taking place from the PMC edge.

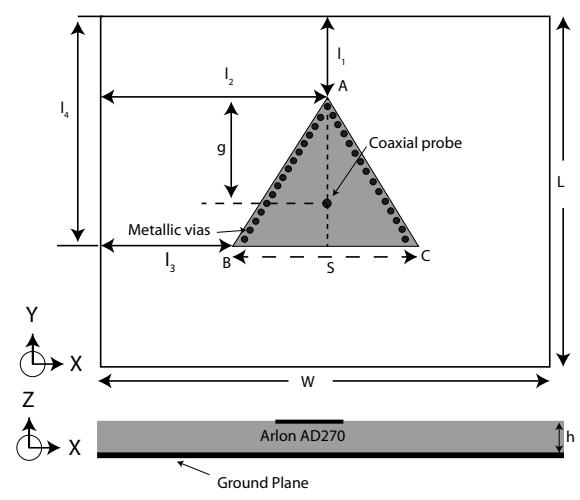

Fig. 1. Schematic diagram of HMSIW equilateral triangular antenna $\left(L=60 \mathrm{~mm}, \quad W=60 \mathrm{~mm}, \quad l_{1}=15 \mathrm{~mm}\right.$ $l_{2}=29.6 \mathrm{~mm}, l_{3}=16.6 \mathrm{~mm}, l_{4}=37.5 \mathrm{~mm}, S=26 \mathrm{~mm}$, $h=0.79 \mathrm{~mm}, g=12 \mathrm{~mm})$. 


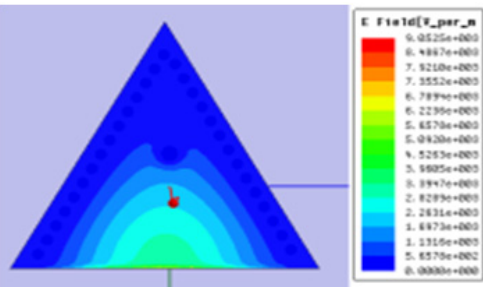

(a)

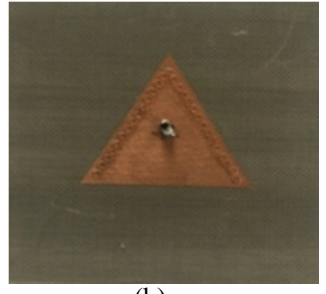

(b)
Fig. 2. (a) Electric-field distribution for $\mathrm{TE}_{101}$ mode at 6.4 GHz and (b) Fabricated antenna prototype.

\subsection{Simulated and Measured Results}

The position of the coaxial feed is varied in order to excite the fundamental $\mathrm{TE}_{101}$ mode with an optimized value of $\mathrm{S}_{11}$ parameter. The parametric study of the feed position carried out is depicted in Fig. 3. From the figure it is evident that the optimized feed location is at $g=12 \mathrm{~mm}$ from the vertex A of the antenna. The simulated input impedance $Z_{\text {in }}$ in Fig. 4.shows the real part of $Z_{\text {in }}$ to be $49.5 \Omega$ and imaginary part being $-2.7 \Omega$ at $6.4 \mathrm{GHz}$ which indicates perfect design for impedance matching of the coaxial feed. With simulated return loss being $-31 \mathrm{~dB}$ at $6.4 \mathrm{GHz}$ covering an impedance bandwidth of $6.37-6.44 \mathrm{GHz}$, i.e $1.1 \%$ fractional bandwidth, the measured return loss with Anritsu VNA is $-25 \mathrm{~dB}$ at $6.5 \mathrm{GHz}$.

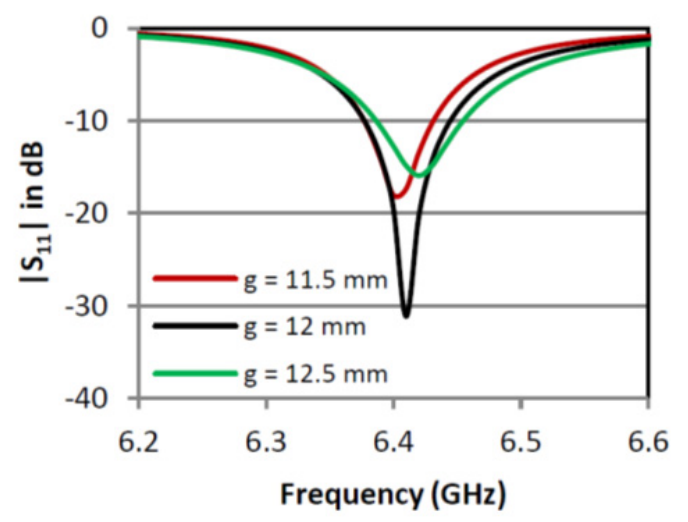

Fig. 3. Variation of $\mathrm{S}_{11}$ with feed point location.

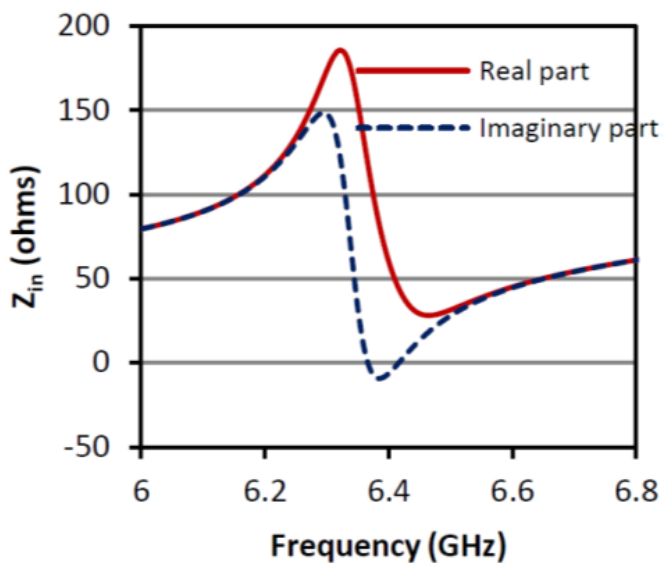

Fig. 4. Input impedance plot of the parent antenna.

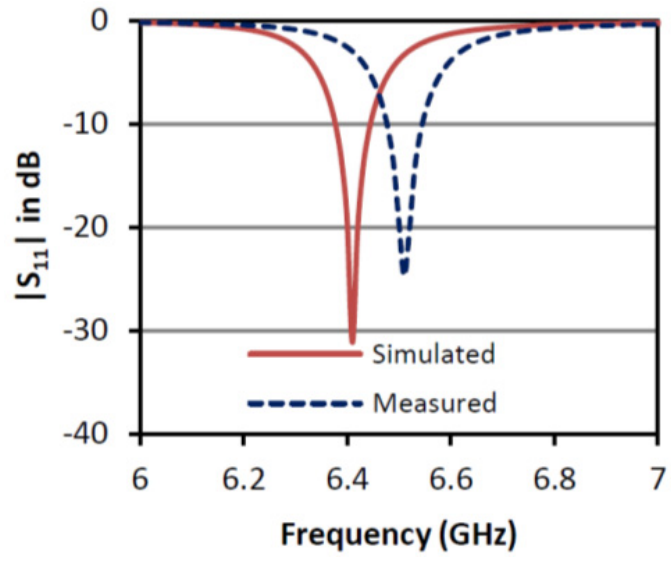

Fig. 5. Return loss characteristic of the parent antenna.

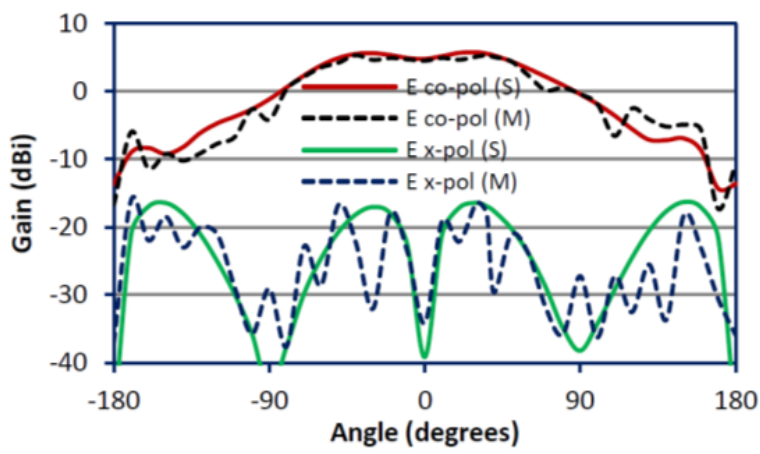

(a)



(b)

Fig. 6. Simulated (S) and measured (M) gain pattern of the antenna at $6.5 \mathrm{GHz}$ : (a) E-plane and (b) H-plane.

A reflection of simulated and measured $\mathrm{S}_{11}$ is shown in Fig. 5. A very slight shift in resonating frequency is accounted for the tolerance factor involved in the manufacturing process of the material and the mismatch associated with the SMA connector in the circuit. The radiation pattern of the designed parent antenna is reflected in Fig. 6. The E-plane plot depicted in Fig. 6(a) reveals a simulated value of $5.5 \mathrm{dBi}$ for the co-pol gain against the measured value of $5.3 \mathrm{dBi}$ while from Fig. 6(b), the simulated and experimentally measured $\mathrm{H}$-plane co-pol gain are $4.8 \mathrm{dBi}$ and $4.5 \mathrm{dBi}$ respectively. The cross-pol values are approximately $25 \mathrm{~dB}$ less than their co-pol values. This designed antenna is thus very suitable for $6.5 \mathrm{GHz}$ based wireless communication systems. 


\section{Antenna with FSS Superstrate}

\subsection{Design Principle of FSS Superstrate}

A schematic diagram depicting the parent antenna fitted with FSS superstrate is depicted in Fig. 7. A bandpass FSS with three cascaded layers of patch [26], as shown in Fig. 8, have been designed to operate at the parent antenna resonating frequency. The design dimensions of the FSS structure are $\mathrm{D} 1=17 \mathrm{~mm}, \mathrm{D} 2=17 \mathrm{~mm}, \mathrm{R} 1=7.5 \mathrm{~mm}$, $\mathrm{R} 2=2.1 \mathrm{~mm}$, height of the FSS superstrate above the antenna is $22.6 \mathrm{~mm}$ and the thickness of the FSS layer is $1.58 \mathrm{~mm}$. The FSS used is made polarization independent with respect to horizontal and vertical polarizations and is thus chosen to be a circular one. It is a combination of twosided layers with $3 \times 3$ array of circular shaped metal patches with the middle layer of metal etched with circular aperture at the center. The resonating frequency and the amount of coupling are all determined by suitably choosing the dimensions of the circular shaped metal patches and apertures. The entire superstrate is fabricated using Arlon AD270 substrate as shown in Fig. 8(b).

The reflection and transmission characteristics of the FSS substrate are simulated using HFSS v15.0 for single as well as $3 \times 3$ elements and the results so obtained are depicted in Fig. 9. As observed from the figure, the reflection coefficient covers an impedance bandwidth of $6.2-6.6 \mathrm{GHz}$ with its transmission coefficient covering frequency from 6 to $6.7 \mathrm{GHz}$ above $-3 \mathrm{~dB}$ level. Thus the parent antenna resonating frequency of $6.5 \mathrm{GHz}$ falls within the passband of the FSS superstrate layer.
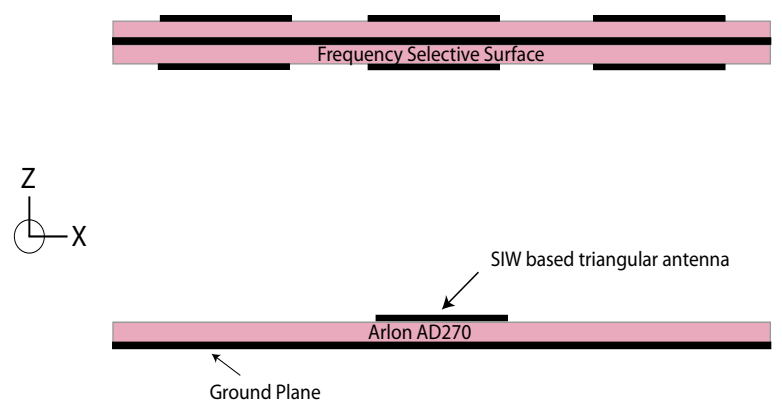

Fig. 7. Schematic view of the parent antenna with FSS superstrate.
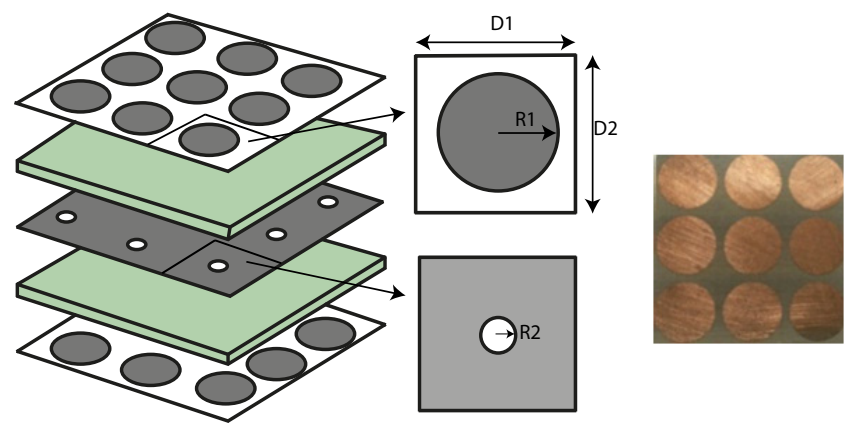

Fig. 8. Configuration of the FSS structure [27] (D1 $=17 \mathrm{~mm}$, $\mathrm{D} 2=17 \mathrm{~mm}, \mathrm{R} 1=7.5 \mathrm{~mm}, \mathrm{R} 2=2.1 \mathrm{~mm})$ and its fabricated prototype (Top view).

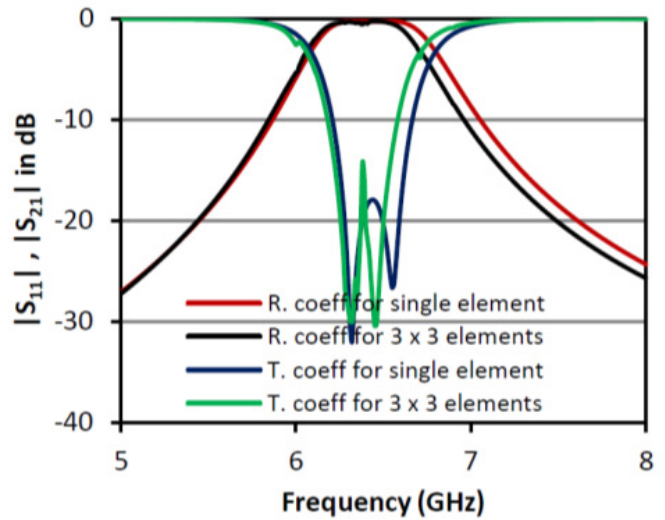

Fig. 9. Simulated $S_{11}$ and $S_{21}$ plot.

The principle of operation of the FSS-Antenna composite structure can be well understood with the help of Fig. 7 and Fig. 9. The FSS is exclusively designed to exhibit bandpass characteristics in the frequency range of 6 to $6.7 \mathrm{GHz}$ as is revealed in the transmission coefficient characteristics of the FSS structure shown in Fig. 9. The phase of the FSS cascaded structure decreases linearly with frequency within the desired frequency band. As is evident from Fig. 7, the waves radiated from the HMSIW triangular antenna suffer small amount of reflection from the lower metallic (patch) layer of the FSS and again get reflected by the ground plane. Thus the total phase delay of this round trip propagation increases linearly with frequency. The variation of phase with frequency, controlled primarily by the spacing between the SIW antenna and the FSS, produces a coherent wave from the composite structure with a zero phase variation thereby reflecting constructive interference of its components leading to gain enhancement over the entire frequency band.

\subsection{Equivalent Circuit of the FSS}

Figure 10(a) represents the equivalent circuit of the FSS layer and is valid for normal incidence of the electro-

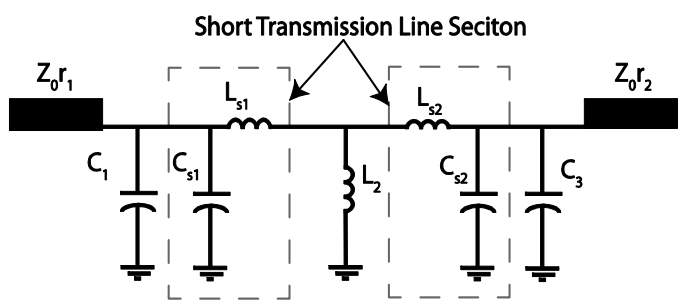

(a)

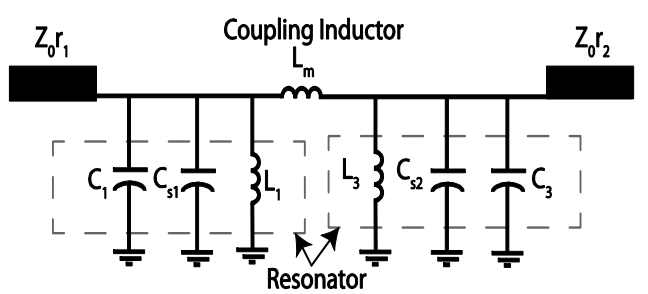

(b)

Fig. 10. (a) Equivalent circuit model of the cascaded FSS structure and (b) second order coupled resonator filter with $\pi$ network [27], [28]. 
magnetic wave [27], [28]. Here $C_{1}$ and $C_{3}$ represent parallel capacitors corresponding to the first and third layers of metallic patches. The parallel inductor $L_{2}$ corresponds to the middle layer of the apertures in the metal. $Z_{0} / V_{\varepsilon_{\mathrm{r} 1}}$ and $Z_{0} / \widehat{\varepsilon}_{\mathrm{r}_{2}}$ are the characteristic impedances of two short pieces of transmission line representing the dielectric substrate separating the three metallic FSS layers. Here $\varepsilon_{\mathrm{r} 1}=\varepsilon_{\mathrm{r} 2}=2.7$ is the dielectric constant of the substrate and $Z_{0}=377 \Omega$ is the characteristic impedance of free space. Figure 10(b) is a conversion of T-network of Fig. 10(a) comprising of $L_{\mathrm{S} 1}, L_{\mathrm{S} 2}$ and $L 2$ into a $\pi$ network comprising of $L_{1}, L_{3}$ and $L_{m}$ whose values can be easily obtained [27], [28]. The spaces at both ends of $3 \times 3$ FSS layer are modeled as semi-infinite transmission line with $Z_{0} r_{1}$ and $Z_{0} r_{2}$ being the respective characteristic impedances $\left(r_{1}=r_{2}=\right.$ normalized source and load impedances $=1$ ).

\subsection{Parent Antenna with FSS Superstrate}

The low profile $3 \times 3$ elements FSS layer with second order bandpass filtering property is placed above the parent antenna at a height of $22.6 \mathrm{~mm}=0.48 \lambda$ for gain augmentation at $6.5 \mathrm{GHz}$ resonating frequency. The fabricated antenna prototype with FSS superstrate is shown in Fig. 11. An Agilent make VNA is used to measure the return loss of the antenna-FSS structure. The simulated and measured return loss for the antenna-FSS combination is depicted in Fig. 12. From the figure it is evident that the measured $S_{11}$ is $-30 \mathrm{~dB}$ at $6.5 \mathrm{GHz}$ against the simulated values of $-25 \mathrm{~dB}$ at $6.4 \mathrm{GHz}$, covering an impedance bandwidth of $6.38-6.44 \mathrm{GHz}$, i.e $0.9 \%$ fractional bandwidth. The radiation pattern measured with the help of Hittite HMC-T2100 microwave signal generator $(10 \mathrm{MHz}$ to $20 \mathrm{GHz})$ and a Krytar 9000B power meter is depicted in Fig. 13. The plot in Fig. 13(a) reveals the simulated and measured

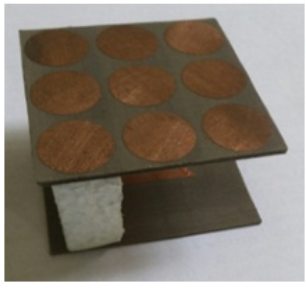

(a)

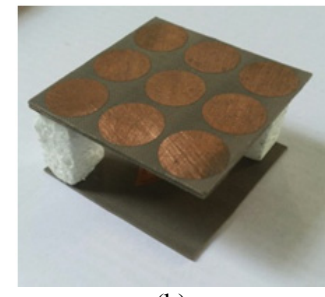

(b)
Fig. 11. Fabricated prototype of the antenna-FSS structure.

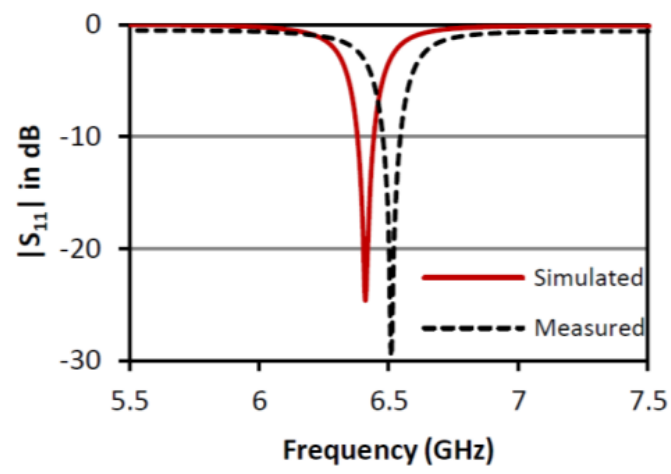

Fig. 12. Return loss characteristic of the antenna-FSS structure.



(a)



(b)

Fig. 13. Simulated $(S)$ and measured $(M)$ gain pattern of the antenna with FSS superstrate: (a) E-plane and (b) Hplane.

E-plane co-pol gain of $8.7 \mathrm{dBi}$ and $8.4 \mathrm{dBi}$ respectively while the same for $\mathrm{H}$-plane are $7.3 \mathrm{dBi}$ and $7 \mathrm{dBi}$ respectively as shown in Fig. 13(b). The cross-pol values for both E- and H-plane are approximately $20 \mathrm{~dB}$ lower than the corresponding co-pol values. Thus clear enhancement of gain from $5.5 \mathrm{dBi}$ to $8.7 \mathrm{dBi}$ is obtained with the incorporation of FSS superstrate.

\section{Conclusion}

For $6.5 \mathrm{GHz}$ wireless communication, a HMSIW based equilateral triangular antenna is developed. The said antenna produces a gain of $5.5 \mathrm{dBi}$ with a narrow fractional bandwidth of $1 \%$. However, owing to the presence of metallic via arrays along two of its sides, the structure produces lesser mutual coupling between two similar elements on account of reduced radiation loss. Thus, arrays using such parent antenna elements could be made in a smaller area with higher antenna gain. A CRSF cascaded FSS superstrate placed above such antenna augments its gain to $8.7 \mathrm{dBi}$ within the desired frequency band thereby reflecting an enhancement of gain by $3.2 \mathrm{dBi}$. Thus such antennaFSS composite structure can be suitably used in proximity of other conductors without any significant electromagnetic interference as the FSS structure would provide the necessary shielding. Thus this combination would be very handy in environments which are very much congested and noisy. 


\section{References}

[1] HIROKAWA, J., ANDO, M. Single-layer feed waveguide consisting of posts for plane TEM wave excitation in parallel plates. IEEE Transaction on Antennas and Propagation, 1998, vol. 46, no. 5, p. 625-630. DOI: 10.1109/8.668903

[2] UCHIMURA, H., TAKENOSHITA, T., FUJI, M. Development of a laminated waveguide. IEEE Transaction on Microwave Theory and Techniques, 1998, vol. 46, no. 12, p. 2438-2443. DOI: $10.1109 / 22.739232$

[3] DESLANDES, D., WU, K. Single-substrate integration technique of planar circuits and waveguide filters. IEEE Transaction on Microwave Theory and Techniques, 2003, vol. 51, no. 2, p. 593 to 596. DOI: 10.1109/TMTT.2002.807820

[4] XU, F., WU, K. Guided-wave and leakage characteristics of substrate integrated waveguide. IEEE Transaction on Microwave Theory and Techniques, 2005, vol. 53, no. 1, p. 66-73. DOI: 10.1109/TMTT.2004.839303

[5] DESLANDES, D., WU, K. Accurate modeling, wave mechanisms and design considerations of a substrate integrated waveguide. IEEE Transaction on Microwave Theory and Techniques, 2006, vol. 54, no. 6, p. 2516-2526. DOI: 10.1109/TMTT.2006.875807

[6] YAN, L., HONG, W., HUA, G., CHEN, J. X., WU, K., CUI, T. J. Simulation and experiment on SIW slot array antennas. IEEE Microwave Wireless Components Letters, 2004, vol. 14, p. 446 to 448. DOI: 10.1109/LMWC.2004.832081

[7] DESLANDES, D., WU, K. Substrate integrated waveguide leaky wave antenna: concept and design considerations. In Proceedings of the Asia-Pacific Microwave Conference (APMC'05). Suzhou, China, 2005.

[8] LUO, G. Q., HU, Z. F., DONG, X. L., SUN, L. L. Planar slot antenna backed by substrate integrated waveguide cavity. IEEE Antennas and Wireless Propagation Letters, 2008, vol. 7, p. 236 to 239. DOI: $10.1109 /$ LAWP.2008.923023

[9] BOHORQUEZ, J. C., PEDRAZA, H. A. F., PINZON, I. C.H., CASTIBLANCO, J. A., PENA, N., GUARNIZO, H. F. Planar substrate integrated waveguide cavity-backed antenna. IEEE Antennas and Wireless Propagation Letters, 2009, vol. 8, p. 1139 to 1142. DOI: 10.1109/LAWP.2009.2034399

[10] AWIDA, M. H., FATHY, A. E. Substrate integrated waveguide Ku-band cavity-backed $2 \times 2$ microstrip patch array antenna. IEEE Antennas and Wireless Propagation Letters, 2009, vol. 8, p. 1054 to 1056. DOI: 10.1109/LAWP.2009.2031416

[11] WANG, H., FANG, D. G., ZHANG, B., CHE, W. Q. Dielectric loaded substrate integrated waveguide (SIW) H-plane horn antennas. IEEE Transaction on Antennas and Propagation, 2010, vol. 58, p. 640-647. DOI: 10.1109/TAP.2009.2039298

[12] XU, J., HONG, W., TANG, H., KUAI, Z., WU, K. Half-mode substrate integrated waveguide (HMSIW) leaky-wave antenna for millimeter wave applications. IEEE Antennas and Wireless Propagation Letters, 2008, vol. 7, p. 85-88. DOI: 10.1109/LAWP.2008.919353

[13] LAI, Q. H., HONG, W., KUAI, Z. Q., ZHANG, Y. S., WU, K. Half-mode substrate integrated waveguide transverse slot array antennas. IEEE Transaction on Antennas and Propagation, 2009, vol. 57, p. 1064-1072. DOI: 10.1109/TAP.2009.2015799

[14] ZELINSKI, G. M., THIELE, G. A., HASTRITER, M. L., HAVRILlA, M. J., TERZOULI, A. J. Half width leaky wave antennas. IET Microwave Antennas and Propagation, 2007, vol. 1, p. 341-348. DOI: 10.1049/iet-map:20060011

[15] MARTINEZ-ROS, A. J., GOMEZ-TORNERO, J. L., GOUSSETIS, G. Planar leaky-wave antenna with flexible control of the complex propagation constant. IEEE Transaction on Antennas and Propagation, 2012, vol. 60, no. 3, p. 1625-1630. DOI: 10.1109/TAP.2011.2180320
[16] BANERJEE, S., RANA, B., PARUI, S. K. Substrate integrated waveguide based triangular antenna arrays. Microwave and Optical Technology Letters, 2016, vol. 58, p. 675-679. DOI: 10.1002/mop. 29645

[17] BANERJEE, S., RANA, B., PARUI, S. K. SIW based compact and dual-band equilateral triangular antennas. Journal of Electromagnetic Waves and Applications, 2016, vol. 30, p. 637-650. DOI: 10.1080/09205071.2016.1142395

[18] BANERJEE, S., RANA, B., PARUI, S. K., CHATTERJEE, S., DEY, N. HMSIW based miniaturized sensing antennas for S- and C-band applications. IEEE Sensors Letters, 2017, vol. 1, no. 1, 4 p. DOI: $10.1109 /$ LSENS.2017.2677858

[19] CHEN, H-Y., TAO. Y. Performance improvement of a U-slot patch antenna using a dual-band frequency selective surface with modified Jerusalem Cross elements. IEEE Transactions on Antennas and Propagation, 2011, vol. 59, no. 9, p. 3482-3486. DOI: 10.1109/TAP.2011.2161440

[20] FOROOZESH, A., SHAFAI, L. Investigation into the effects of the patch-type FSS superstrate on the high-gain cavity resonance antenna design. IEEE Transactions on Antennas and Propagation, 2010, vol. 58, no. 2, p. 258-270. DOI: 10.1109/TAP.2009.2037702

[21] PIRHADI, A., BAHRAMI, H., NASRI, J. Wideband high directive aperture coupled microstrip antenna design by using a FSS superstrate layer. IEEE Transactions on Antennas and Propagation, 2012, vol. 60, no. 4, p. 2101-2106. DOI: 10.1109/TAP.2012.2186230

[22] ATTIA, H., YOUSEFI, L., RAMAHI, O. High-gain patch antennas loaded with high characteristic impedance superstrates. IEEE Antennas and Wireless Propagation Letters, 2011, vol. 10, p. 858-861. DOI: 10.1109/LAWP.2011.2165196

[23] HOSSEINI, A., CAPOLINO, F., FLAVIIS, F. D. Gain enhancement of a V-band antenna using a Fabry-Pérot cavity with a self-sustained all-metal cap with FSS. IEEE Transactions on Antennas and Propagation, 2015, vol. 63, no. 3, p. 909-921. DOI: 10.1109/TAP.2014.2386358

[24] LEE, D. H., LEE, Y. J., YEO, J., MITTRA, R., PARK, W. S. Design of novel thin frequency selective surface superstrates for dual-band directivity enhancement. IET Microwaves Antennas and Propagation, 2007, vol. 1, no. 1, p. 248-254. DOI: 10.1049/ietmap:20050318

[25] VAIDYA, A. R., GUPTA, R. K., MISHRA, S. K., MUKHERJEE, J. Efficient, high gain with low side lobe level antenna structures using parasitic patches on multilayer superstrate. Microwave and Optical Technology Letters, 2012, vol. 54, no. 6, p. 1488-1493. DOI: $10.1002 / \operatorname{mop} .26818$

[26] ZHOU, H., QU, S., LIN, B., WANG, J., MA, H., XU, Z., PENG, W., BAI, P. Filter-antenna consisting of conical FSS radome and monopole antenna. IEEE Transactions on Antennas and Propagation, 2012, vol. 60, no. 6, p. 3040-3045. DOI: 10.1109/TAP.2012.2194648

[27] RANA, B., CHATTERJEE, A., PARUI, S. K. Gain enhancement of a dual-polarized dielectric resonator antenna using polarization independent FSS. Microwave and Optical Technology Letters, 2016, vol. 58, no. 6, p. 1415-1420. DOI: 10.1002/mop.29832

[28] CHATTERJEE, A., PARUI, S. K. Gain enhancement of a wide slot antenna using a second-order bandpass frequency selective surface. Radio Engineering, 2015, vol. 24, no. 2, p. 455-461. DOI: 10.13164/re.2015.0455

[29] ZHOU, H., QU, S., XU, Z., LIN, B., WANG, J., MA, H., BAI, P., PENG, W. A compact second-order Frequency Selective Surface with broadband response. Microwave and Optical Technology Letters, 2012, vol. 54, no. 2, p. 392-394. DOI: 10.1002/mop.26532

[30] LAI, Q., FUMEAUX, Ch., HONG, W., VAHLDIECK, R. Characterization of the propagation properties of the half-mode substrate integrated waveguide. IEEE Transaction on Microwave 
Theory and Techniques, 2009, vol. 57, no. 8, p. 1996-2004. DOI: 10.1109/TMTT.2009.2025429

[31] POZAR, D. M. Microwave Engineering. $3^{\text {rd }}$ ed. New York (USA): Wiley, 2005. ISBN: 978-0-470-63155-3

[32] SAUER, T. Numerical Analysis. Upper Saddle River (NJ, USA): Person Educ., 2006. ISBN-13: 9780321783677

[33] FENG, X., WU, K. Guided-wave and leakage characteristics of substrate integrated waveguide. IEEE Transaction on Microwave Theory and Techniques, 2005, vol. 53, no. 1, p. 66-73. DOI: 10.1109/TMTT.2004.839303

[34] DESLANDES, D., WU, K. Integrated microstrip and rectangular waveguide in planar form. IEEE Microwave Wireless Components Letters, 2001, vol. 11, no. 2, p. 68-70. DOI: 10.1109/7260.914305

\section{About the Authors...}

Soumen BANERJEE (1976) received his B.Sc (Honours) degree in Physics, B.Tech and M.Tech degrees in Radio Physics and Electronics from the University of Calcutta. $\mathrm{He}$ is a faculty at the University of Engineering \& Management, Kolkata, India. He was the visiting faculty at the Dept. of Applied Physics, University of Calcutta and is presently associated with research activities at the Indian Institute of Engineering Science and Technology (IIEST), Shibpur, India. His research interests include design, fabrication and characterization of wide band gap semiconductor based Impatt diodes at D-band, W-band and
THz frequencies, SIW technology based antennas, printed antennas and arrays. He has published more than 50 contributory papers in journals and international conferences.

Biswarup RANA (1985) has received his Ph.D. degree at the Indian Institute of Engineering Science and Technology (IIEST), Shibpur, India in 2017. His research interest includes analysis and design of microstrip antennas, substrate integrated wave guide antennas, phased array antennas, dielectric resonator antennas etc. He has published more than 40 papers in journals and international conferences.

Susanta Kumar PARUI (1965) received B.Sc degree in Physics and B.Tech. degree in Radio Physics and Electronics from the University of Calcutta in the year 1987 and 1990 respectively. He obtained M.E degree in 1993 and received Ph.D from the Bengal Engineering and Science University, Shibpur, India in 2009. Since 2000 he is associated with the Dept. of Electronics and Telecommunication Engineering, Indian Institute of Engineering Science and Technology, Shibpur, India and presently holds the post of Associate Professor. He was awarded post doctorial fellowship from the Royal Academy of Engineering, U.K in the year 2009. His current research interests include planar circuits, antennas, SIW, DGS, EBG and meta-materials. He has published over 100 papers in journals and international conferences. 